\title{
Three Conceptions of Practical Authority
}

\author{
Daniel Star and Candice Delmas*
}

Joseph Raz's much discussed service conception of practical authority has recently come under attack from Stephen Darwall, who proposes that we instead adopt a second-personal conception of practical authority. ${ }^{1}$ In sharp contrast to both Darwall and Raz, we believe that the best place to begin understanding practical authority is with a pared back conception of it, as simply a species of normative authority more generally, where this species is picked out merely by the fact that the normative authority in question is authority in relation to action, rather than belief. We call this the minimalist conception of practical authority. ${ }^{2}$ We do not wish to deny that there might turn out to be substantive properties of practical authority that are peculiar to it (apart from the mere property of being the species of authority that is concerned with action), but, unlike both Raz and Darwall, we do not believe that such features play a fundamental role in defining or delimiting practical authority. We hope that this third conception of authority will appear particularly attractive coming, as it will, on the heels of a comparison of the alternatives.

We begin, in section I, with a discussion of Darwall's and Raz's accounts of practical authority (readers who are already very familiar with the details of the debate between Darwall and Raz may wish to skip this section). Next, in section II, we consider what we take to be Darwall's dialectically strongest criticism of Raz, concerning which we end up siding with Raz. Finally, in section III, we focus on the concept of authority afresh, and suggest that our alternative conception of practical authority provides a better starting place for future discussions of authority than either of the

* Daniel Star is an assistant professor of philosophy at Boston University, USA; Candice Delmas is a PhD candidate in philosophy at Boston University, USA.

1 We are grateful to Stephen Darwall for visiting the Boston University Ethics Reading Group to discuss his work on practical authority with us, and for his feedback on an early draft of our paper. We would also like to thank an anonymous referee, whose comments were very helpful.

2 More specifically, Daniel Star, as the author of section III of the present paper, calls this the minimalist conception of authority. He is developing a fuller account of this conception of authority in separate work, where he aligns the authority of normative reasons in general with the authority of evidence, using the reasons as evidence account of normative reasons first defended in Stephen Kearns and Daniel Star, 'Reasons: Explanations or Evidence?' (2008) 119 Ethics 31-56. This enables him to provide an alternative explanation for the existence of preemptive and exclusionary reasons to the one that Raz has provided, as part of an account of reasons that allows for preemptive and exclusionary reasons to play a more general role than Raz believes that they play, thereby providing a unified explanation of the fact that they appear not only in the practical domain, but also in the epistemic domain. 
other conceptions. Our sketch of this minimalist conception includes a short discussion of the relation between it and some very general and highly plausible claims about normativity.

\section{DARWALL AND RAZ ON PRACTICAL AUTHORITY}

Raz and Darwall both seek to explain the grounding of claims of practical authority, which they take to be authority of the kind one person has over the will of another, in relation to the other person's actions. Darwall argues that practical authority can only be justified from the second-person standpoint, which we take up whenever we address or acknowledge a moral claim or demand. Raz, on the other hand, contends that legitimate practical authority is grounded in the fact that a legitimate authority's directives enable any person who is subject to that authority to better conform to their own reason than they would otherwise be able to. Neither of these claims is immediately perspicuous, so we must begin by explaining them.

Darwall outlines and defends his original account of practical authority in The Second-Person Standpoint. As he understands it, practical authority involves a certain type of relation between an addresser $\mathrm{A}$ and an addressee $\mathrm{B}$, such that a directive that originates from A gives B a special type of reason for acting as A demands, ie a 'second-personal' reason. Second-personal reasons spring from claims or demands that address an agent, and presuppose the addresser's authority to make such claims, as well as the addressee's 'second-personal competence', ie a capacity to acknowledge the claim as valid, and to act accordingly. 'When someone attempts to give another a second-personal reason,' Darwall writes, 'she purports to stand in a relevant authority relation to her addressee. ${ }^{3}$ Practical authority involves not merely a logical (or metaphysical) relation-rather, it is 'a standing in a relationship'. ${ }^{4}$ That being said, certain things do logically follow from any authority claim, with respect to what the addresser and the addressee owe each other. In particular, if A has authority with respect to B, then not only do A's directives generate reasons for B to follow those directives, but they also mean that B is morally responsible for acting or failing to act on these reasons, and answerable to A if she does not so act. The claims and demands we make on one another presuppose, and take place from within, a structure of reciprocal address dubbed the 'second-person standpoint'.

Darwall argues that 'to enter intelligibly into the second-person stance and make claims on and demands of one another at all ... you and I must presuppose that we share a common second-personal authority, competence, and responsibility simply as free and rational agents'. ${ }^{5}$ If I make a claim on you, I imply that I have the authority to do so, and that you have the competence to recognise my claim as valid, and

3 Stephen Darwall, The Second-Person Standpoint (Harvard University Press, 2006) 4, emphasis added.

4 Stephen Darwall, 'Authority, Accountability, and Preemption' (2011)2(1) Jurisprudence 103-19, 109 (this issue). In The Second-Person Standpoint (n 3), Darwall similarly writes, "whether a reason is second-personal is a matter not of logical relations but of personal relations' (11).

5 Darwall (n 3) 5, emphasis added. 
thus respond appropriately. And if you accept my claim as valid, you thereby acknowledge that I have grounds for complaint, and perhaps compensation, if you do not do as I demand. The second-person standpoint thus provides the key to the distinction between second-personal reasons and practical reasons that are not second-personal: unlike other practical reasons, (i) second-personal reasons are grounded in, and addressed from within, certain normative authority relations that the addresser takes to hold between her and her addressee; and (ii) second-personal reasons make a distinctive kind of claim on the will in that they commit both parties to seeing each other as free and rational beings, ie 'self-originating sources of claims' (to use a phrase from Rawls that is in the epigraph of the first chapter of Darwall's book).

We just said that, on Darwall's picture, reasons for action created by practical authorities are distinct from practical reasons of other sorts in that they are grounded in certain authority relations, and, before that, that these authority relations can only be understood in terms of second-personal reasons. This sounds quite circular! In fact, Darwall not only explicitly recognises this circularity, but positively celebrates it: 'These notions-second-personal authority, valid claim or demand, second-personal reason, and responsibility to ... comprise an interdefinable circle; each implies all the rest. ${ }^{6}$ This is to say that the second-person standpoint is constituted by a circle of four irreducibly second-personal notions, such that, wherever there is genuine practical authority, the application of three other concepts is appropriate: first, there must be a valid claim or demand; second, the subject must be accountable or responsible to the authority; and third, there must be a second-personal reason for acting in conformity with the claim under consideration (and so discharging the corresponding responsibility).

Furthermore, according to the irreducibility thesis at the core of Darwall's account of the second-person standpoint, the core second-personal notions are irreducible, in that their legitimate application can neither be adequately explained by, nor wholly generated by, non-second-personal considerations. He stresses that this means that 'there is no way to break into this circle from outside it'. ${ }^{7}$ No proposition that does not already involve second-personal notions can entail any that does. An important implication of this thesis is that 'No authority to make claims and demands can be based entirely on non-second-personal reasons' ${ }^{8}$

Note that the legitimacy of a claim need not depend on the particular, unique position of the person who makes it. Second-personal addresses, according to Darwall, do not only occur between someone who holds a right (such as, to use Darwall's example, the right not to have one's foot stepped on) and another particular person who might violate it. He distinguishes two main aspects of the second-personal conception of practical authority. The first is a particular right-holder's special standing to demand that people respect her rights, and to hold those who violate them accountable. The second is the authority anyone has, 'as a representative of

Ibid, 12.

Ibid.

Darwall, 'Authority, Accountability, and Preemption' (n 4) 105. 
the moral community', to blame any wrongdoer, or to hold him or her responsible through reactive attitudes such as indignation. ${ }^{9}$

Darwall thinks we focus on the first aspect of practical authority whenever we are considering moral rights, and on the second aspect of practical authority whenever we are considering moral obligation more generally. With respect to both aspects, practical authority essentially requires the standing to hold accountable, and is intimately connected to the possession of reactive attitudes-one typically holds people accountable through manifesting reactive attitudes such as blame and resentment, and one can hold oneself responsible through manifesting attitudes such as remorse and guilt. By their nature, reactive attitudes essentially address charges to their objects, and they 'involve or presuppose a view of their objects as having some competence to understand or appreciate the charge'. ${ }^{10}$

What arguments does Darwall provide in support of his overall theory? A good deal of his argumentation in The Second-Person Standpoint is done from within the second-personal circle, by thinking through crucial moral concepts-eg rights, persons, dignity - and arguing that each necessarily relies on the four irreducible second-personal notions. We take it that the coherence, intuitive appeal and elegance of Darwall's theory are supposed to weigh in its favour. Darwall also provides support for his view by arguing against rival theories, especially those that suppose or affirm that claims of practical authority can be justified on the basis of non-second-personal reasons. For instance, in the ninth chapter of his book, he argues that Kantian attempts to vindicate morality from within the first-person standpoint of a deliberating agent cannot succeed. In a series of recent articles, Darwall attacks another prominent non-second-personal-this time third-personal-account of practical authority, namely, Raz's service conception. Before we discuss the arguments that form the basis of this attack, we need to very briefly describe this alternative conception.

In contrast to Darwall's account of what is needed to justify claims of practical authority, Raz's account is clearly not second-personal. According to Raz, practical authority is normally justified if: (1) the subject is likely to better conform with reasons which already, independently, apply to her if she intends to accept the authority's directives and treat them as valid; and (2) the relevant situation is one where it is better that the agent conforms with the reasons that externally apply to her, rather than decide for herself what to do without the aid of an authority. ${ }^{11}$ Raz dubs the first of these conditions the normal justification thesis (NJT), and the second the independence condition. We will follow Darwall in focusing on the NJT here.

According to Raz, agents that are subject to an authority that satisfies these conditions will find themselves with new, derivative reasons for action. These 'preemptive' reasons are reasons that follow directly from the authority's directives and are to be considered without considering independent reasons that might con-

$9 \quad$ Ibid, 107.

10 Ibid, 109.

11 Joseph Raz, 'The Problem of Authority: Revisiting the Service Conception' (2006) 90 Minnesota Law Review 1003-44, 1014. It should be said that Raz's own exact statement of the independence condition is a little unclear. 
flict with them: a reason of this type is not to be added to all other relevant reasons when assessing what to do, but should exclude and take the place of some of them'. ${ }^{12}$ For example, a person driving down a highway might, very plausibly, be thought to have a preemptive reason to drive no faster than a sign-posted speed limit, where this reason also speaks against her attempting to independently determine the fastest speed at which it might be safe for her to drive. Very plausibly, such a person better conforms with independent reasons that already apply to her in the long term by treating the speed limit as authoritative than she would if she considered nonauthority-based reasons, with respect to the issue of determining the fastest speed at which she might drive. And on Raz's account of practical reasons, this means not merely that she should treat the speed limit as if it provides a genuine reason for action, but instead that the speed limit provides a genuine reason for action (a reason that can be classified as preemptive) in virtue of the fact that the person who follows it better conforms with independent reasons in the long term.

Raz says he broadly understands practical authority to be 'authority with power to require action'. ${ }^{13}$ That being said, he thinks that exercises of practical authority are distinct from exercises of coercive power, in that they include 'an appeal for compliance by the person(s) subject to the authority ... an invocation of the duty to obey'. ${ }^{14}$ Whether a duty to obey really exists for a subject depends on whether the relevant putative authority actually possesses the right to rule it claims to have. If it does, then its authority is de jure, otherwise, it is merely de facto. It is important to note that the mere possession of a legitimate justification for the use of force on the part of a de facto authority is not enough to make it an authority de jure. ${ }^{15}$ According to the service conception, the authority must serve the governed, protect and promote their interests, and generally help them secure better conformity with reason.

On Raz's account, a political authority cannot normally be legitimate unless it is effective at getting people to obey its commands through changing the reasons that apply to its subjects:

12 Joseph Raz, The Morality of Freedom (Oxford University Press, 1986) 46. The relation between preemptive reasons and 'exclusionary' reasons is complicated, and the complications will be ignored here. Suffice to say that Raz thinks that it is usually fine to focus on the above type of characterisation of preemptive reasons alone when considering the nature of authority, but he also thinks that he can tell a deeper story about preemptive reasons where we understand them to be 'protected' reasons, where a protected reason is a fact that constitutes a first-order reason to do a particular act and an exclusionary reason 'not to fail to [do this particular act] for a certain range of excluded reasons' (Joseph Raz, 'On Respect, Authority, and Neutrality: A Response' (2010) 120 Ethics 279-301, 298). For a definition of 'exclusionary reason' as a second-order reason to refrain from acting on a firstorder reason, see Joseph Raz, Practical Reason and Norms (Princeton University Press, 1990 [1975]) 39.

13 Joseph Raz, 'Authority and Justification' (1985) 14 Philosophy and Public Affairs 3-29, 3.

14 Raz, The Morality of Freedom (n 12) 25-26.

15 Raz dissociates the commonly entangled concept of justification of the use of force from that of authority by discussing an example: 'I do not exercise authority over people afflicted with dangerous diseases if I knock them out and lock them up to protect the public, even though I am, in the assumed circumstances, justified in doing so' (Raz (n 13) 5.) One can think that the measures taken by a local political authority during an epidemic are morally justified without thereby judging that the government is legitimate. 
$[\mathrm{I}] \mathrm{n}$ most cases the normal justification cannot be established unless the putative authority enjoys some measure of recognition, and exercises power over its subjects. There is a strong case for holding that no political authority can be legitimate unless it is also a de facto authority. For the case for having any political authority rests to a large extent on its ability to solve co-ordination problems and extricate the population from Prisoner's Dilemma type situations. ${ }^{16}$

Governments can generally only succeed in meeting conditions of legitimacy if they are successful in the use of force against those who flout certain of their directives. In turn, subjects could not have reasons to accept directives as binding if political authorities did not have power to force compliance, which is crucial to any state's ability to solve coordination problems. Normally, for a political authority to fulfill its function it must have the capacity to replace other reasons for action that people might have, and thus reliably guide coordinated action.

Of course, it is important to recognise that Raz does not wish to claim that the power to require action is essential to justifying every kind of practical authority. Much of the time, he focuses his discussion on authority in the political domain, but his account is ultimately meant to have very general application. Nonetheless, power is connected to the capacity to create preemptive reasons in normal political cases, where it contributes to the justification of the authority in place. In contrast, Darwall does not think that the possession of de facto authority is even relevant to establishing a claim to practical authority. This can be inferred from his theory: ${ }^{17}$ just because someone is powerless, it does not even generally follow that she does not have a valid claim that others follow her directives (to respect her rights, say).

Raz's NJT constitutes a straightforward challenge to Darwall's irreducibility thesis, since the latter must be incorrect if the NJT is correct. ${ }^{18}$ Recall that on Darwall's alternative conception of practical authority, one is only in a position to be an authority in relation to another person when one has the normative standing to make a morally valid second-personal demand of the other person. So, for example, if someone is stepping on my foot, I have the standing to authoritatively assert my right that he not do so, and you have a different type of standing to demand that he not do so, due to the fact that you are 'a representative of the moral community, whose members understand themselves as holding one another to a (moral) demand not to step on each other's feet'. ${ }^{19}$ Neither type of standing is something one could acquire on the basis of the expected consequences of compliance with a directive, even given a putative authority's superior knowledge: 'The standing itself neither is, nor simply follows from, any form of third-personal or epistemic authority. ${ }^{20}$

16 Raz, The Morality of Freedom (n 12) 56.

17 Darwall expressly defended the point as he answered questions following his presentation at the Boston University Ethics Reading Group, 12 February 2010. It is also suggested in a footnote in the article we are responding to (Darwall, 'Authority, Accountability, and Preemption' (n 4) 116 n 40).

18 A conflict between the Irreducibility Thesis and the NJT would not arise (or would not arise in the same way) if Darwall were to claim that all normative reasons are second-personal, but this is clearly something he does not wish to do.

19 Stephen Darwall, 'Authority and Second-Personal Reasons for Acting' in David Sobel and Steven Wall (eds), Reasons for Action (Cambridge University Press, 2009) 134-54, 136.

20 Darwall (n 3) 13. 
The objection that Darwall is concerned to forestall can be put like this: if the reasons with which a subject would better comply with another's directives are not second-personal themselves, then a person could acquire authority over someone else owing entirely to non-second-personal considerations; hence the irreducibility thesis is false. Darwall must therefore take issue with the NJT, as providing something like a sufficient condition for practical authority. ${ }^{21}$

Darwall responds to this objection in three recent papers, where he continues to argue that no claims of practical authority can be exclusively justified by non-secondpersonal reasons. He mainly criticises Raz's NJT as a general condition of authority, attempting to show that it is only plausible when the reasons with which the subject might best comply already themselves assume background accountability relations that are critical to establishing the authority's legitimacy. To wit, the NJT only succeeds when the dependent reasons are second-personal reasons-but then it fails to provide any basis for a third-personal account of practical authority.

In his 'Authority and Second-Personal Reasons for Acting', ${ }^{22}$ Darwall purports to show that Raz's account fails to capture an essential aspect of practical authority, namely, its intrinsic connection to the standing to hold accountable. In 'Authority and Reasons: Exclusionary and Second-Personal', ${ }^{23}$ Darwall credits Raz for discovering that practical authority involves the capacity to create preemptive reasons, but argues that the NJT fails as a standard for determining when it is the case that genuine preemptive reasons are actually present. The article we are responding to, 'Authority, Accountability, and Preemption' (in the present issue of this journal), draws on these two earlier articles. Darwall emphasises here that he agrees with Raz that the capacity to create preemptive reasons is a mark of practical authority, but also stresses that, unlike Raz, he believes that this capacity requires the second-personal relation of accountability. This thought is summed up by a slogan: 'No preemptive reasons without the standing to hold accountable'. ${ }^{24}$

In his attempts to rebut the Razian challenge to the Irreducibility Thesis, Darwall's recent arguments basically rely on two main moves: (1) the drawing of a wrong kind of reasons diagnosis; and (2) the provision of purported counterexamples to the NJT which, if they are genuine counterexamples, might best have their status as counterexamples explained by (1). Darwall hopes to elicit some firm intuitions or judgments about the particular cases he discusses. We mostly focus on these cases and intuitions in the next, critical section of the paper, since we do not deny that they initially carry some weight, and because, prima facie, they are dialectically neutral (hence are less likely to lead to a charge that Darwall is begging the question).

The wrong kind of reasons diagnosis is not dialectically neutral, since acceptance of it requires one to reject the third-person standpoint (or, at least, view it as having lit-

21 In fact, Raz does not intend the NJT to be a sufficient condition, since he also puts weight on the independence condition, but we take it that Darwall thinks of this second condition as being of only subsidiary importance.

22 Darwall (n 19).

23 Stephen Darwall, 'Authority and Reasons: Exclusionary and Second-Personal' (2010) 120 Ethics 121.

24 Darwall, ‘Authority, Accountability, and Preemption' (n 4) 106. 
tle importance when it comes to justifying moral judgments), and follow Darwall into the irreducible circle at the heart of the second-person standpoint. ${ }^{25}$ This diagnosis is already at centre stage in Darwall's book, where he calls it 'Strawson's Point'. Darwall takes Strawson to have demonstrated in 'Freedom and Resentment' 26 that there are reasons of the right kind and reasons of the wrong kind when it comes to the justification of moral practices. In particular, desirability is a reason of the wrong kind to warrant the attitudes and actions involved in holding someone responsible. 'To be a reason of the right kind,' Darwall contends, 'a consideration must justify the relevant attitude in its own terms. ${ }^{27}$ So, for instance, Mill's claim that a practice of protecting certain putative rights would maximise benefits and minimise suffering, even if true, would not show that we actually have such rights. ${ }^{28}$ The claim that only an internal perspective is permissible when attempting to justify a reactive attitude might be true, but we should not forget that Darwall's particular use of the wrong kind of reasons diagnosis will be considered highly questionable by many moral philosophers (especially, but not only, consequentialists of various stripes).

While Raz continues to defend the view that practical authority involves the capacity to create preemptive reasons, he rejects the idea that practical authority involves a standing to hold accountable. In a long reply to Darwall, Raz criticises Darwall's analysis of the concepts of 'standing' and 'accountability', as well as his account of rights and duties. ${ }^{29} \mathrm{He}$ also makes it clear that he takes their projects to be very different:

My explanation of authority is an attempt to explain authority over people of the kind that governments claim to have over their subjects, parents over their children, and so on. It does not purport to be part of an account of rights and duties in general, as Darwall's own writings on authority are. ${ }^{30}$

Raz understands Darwall to be concerned with the permissions moral agents have to demand performance of (already existing) duties, or compensation for their breach, while he himself is interested in the power to impose new duties on people; that is, the capacity to create preemptive reasons. Although the underpinnings of their projects are very different, Darwall does not think of Raz as focusing on a different concept of authority than the one that he is interested in, so we do have a deep disagreement here, and not just a superficial verbal dispute (as might occur if two people were simply using different concepts, rather than arguing about different conceptions of one concept). Both Raz and Darwall claim to be elucidating the ordinary

25 To avoid confusion, it should be said that we do not mean to be committed to anything at all to do with the more commonly referred to 'wrong kind of reasons problem' for buck-passing accounts of evaluative properties (and this is not Darwall's concern, either, despite his potentially confusing use of the same phrase).

26 PF Strawson, 'Freedom and Resentment' in Studies in the Philosophy of Thought and Action (Oxford University Press, 1968) 71-96.

27 Darwall (n 3) 16.

28 Darwall, 'Precis: The Second-Person Standpoint' (2010) 81(1) Philosophy and Phenomenological Research 21628, 218.

29 Raz, 'On Respect, Authority, and Neutrality' (n 12).

30 Ibid, 290. 
concept of authority, and not some more circumscribed concept. ${ }^{31}$ The service conception offers an attractive and plausible account of political authority. And if Raz is correct that political authority can normally be justified on the basis of considerations such as actual power and the desirability of subjects treating directives as binding, then the irreducibility thesis must be false.

\section{DEFUSING DARWALL'S ARGUMENT AGAINST THE NORMAL JUSTIFICATION THESIS}

Darwall contends that meeting the NJT is neither necessary nor sufficient for establishing that some person or institution is a legitimate authority. This disagreement with Raz might be thought to incorrectly rest on a presupposition that the NJT provides a complete account of legitimacy. Yet, as we noted in the first section of this paper, the NJT offers an account of the way legal and political authority is normally justified: it is not the only way to justify a claim that someone has legitimate authority; as Raz says, 'it is ... the normal one'. ${ }^{32}$ Nonetheless, we can assume from Raz's recent response to Darwall that the cases that Darwall suggests are counterexamples are normal enough that they are not to be dismissed as counterexamples merely on the grounds of abnormality. ${ }^{33}$

Darwall provides a series of apparent counterexamples to the proposition that the NJT lays down the conditions for determining when a putative authority's directives actually provide subjects with preemptive reasons. To take one such example: even though it may be desirable for me to treat an alarm clock's authoritative voice recording ('You must get out of bed now!') as a binding order, this does not mean that its directive actually preempts the reasons I have to stay in bed. I do not, Darwall claims, now possess a preemptive reason to get out of bed that would have me exclude reasons to fall back to sleep. Nor does it follow that the alarm clock has acquired authority over me or that I can be blamed for my failure to comply with its directive. What the alarm clocks lacks, according to Darwall, is the standing to issue directives to others and the capacity to hold them accountable, so it simply cannot have the capacity to create preemptive reasons. Furthermore, he claims that it will make no difference to our judgement regarding the lack of such a standing, and the practical authority that would go with this standing if it were there, if we instead imagine that I have hired a person to come by my bed and provide me with an 'authority experience'. ${ }^{34}$

31 Darwall has confirmed in email correspondence that he aims to be giving an account of the ordinary concept of authority. We take ourselves to be discussing three conceptions of one concept in this paper, and not three different concepts, although we are inclined to think (with Raz) that Darwall's account of authority would work better if it were repackaged as an account of a more limited concept. Raz seems to be suggesting that Darwall might be using a different concept of authority in 'On Respect, Authority, and Neutrality' (n 12) 290-2, but we do not think this matters too much for our purposes, given that Darwall does not view things this way. Raz, The Morality of Freedom (n 12) 53.

33 Raz, 'On Respect, Authority, and Neutrality' (n 12) 297-301.

34 The examples, as well as the quoted phrase, are from Darwall, 'Authority, Accountability, and Preemption' (n 4) 113-16. 
We might here deny the verisimilitude of Darwall's intuitions, and hold that the alarm clock, or at least a person doing the job of an alarm clock, could have practical authority over B. Suppose B were to hire a personal life coach to help him improve his work ethic and discipline. The coach's orders to get out of bed at 7 am would then clearly satisfy the NJT and be genuinely binding on B. Darwall would reply that it would be very odd to think that we can hold B morally accountable to his coach, and that the coach thus lacks the standing to create preemptive reasons. ${ }^{35}$

We suspect the intuitions Darwall relies on here do not withhold scrutiny, unless one has already accepted that interpersonal moral authority is the one true kind of practical authority. Darwall denies that talk of authority and accountability, rights and duties, is appropriate in cases involving prudence, but we believe that he does not provide sufficient (non-question-begging) reasons to cordon off practical authority to the exclusive sphere of interpersonal morality. One could, on the contrary, quite plausibly criticise B for failing to comply with his coach's orders, from the point of view of prudence (rather than morality), and construe the coach as possessing the capacity to create preemptive reasons to the extent that they are in B's own interest (even if one would not go so far as to blame B for any failure to follow his coach's directives). B might thereby be taken to have sufficient reason to accept his coach's directives as legitimate, and the coach in turn would have practical authority over B. On our minimalist conception of authority we would further add that since such a coach would have practical authority over B, we don't see any reason to suppose an alarm clock could not have practical authority (in the most general sense) over B.

As Darwall is aware, Raz considered in earlier work how best to respond to a variation on the criticism that Darwall provides. ${ }^{36}$ Raz considers a case of a man who goes to a cooking class and decides not to follow his teacher's instructions at some point during the class. To the criticism that it does not look like the teacher has the authority to demand that the man in the cooking class follow his instructions-even when his directives are the kind that should provide preemptive reasons according to the NJT-Raz replies that we can explain away this intuition. What is needed, he thinks, is for us to bear in mind that being able to make autonomous decisions is plausibly an important aspect of wellbeing (one might add that spontaneity and creativity further constitute important goods that would be ignored if the teacher were to be dictatorial in his response). However, Darwall thinks that even if we alter the case to make it one where all the man who attends the class wants is to cook as well as possible, we still will not come to accept that the teacher possesses the authority to demand compliance with his directives. ${ }^{37}$

We would like to provide a different response that complements, rather than contradicts, the response we just took from Raz: we think it is important to bear in mind

One might also be concerned that the fact that the life coach was willingly employed to give directives, and did not just appear out of nowhere to give such directives, is playing a role in relation to our intuitions. We are grateful to an anonymous referee for raising this concern. We address it below.

37 Darwall (n 19) 151. 
that what might be fuelling counter-authority intuitions in such cases (that is, cases that involve prudential, rather than moral, reasons), to the extent that people might be inclined to share Darwall's intuitions, may be general ignorance about what is genuinely in the best interests of other people. Plausibly, we are rarely, if ever, in a good epistemic position vis-à-vis the truth about what is best for other adults' lives, especially when we limit our attention to cases where what is at issue are various ways of improving another individual's life. ${ }^{38}$ This is because we are very unsure about what is the correct, principled way to weigh the factors that contribute to wellbeing, and even whether wellbeing depends on preference-satisfaction, or the balancing of goods on an objective list, or factors that might be specified by some other general theory of wellbeing. We also very often have at least some degree of ignorance about all the prudentially relevant non-evaluative facts-especially the relevant preferences of the person we are considering.

However, if we simply imagine a teacher being in a state of complete knowledge about what is actually best for her adult student, and the adult student being epistemically justified in accepting that the teacher is knowledgeable in this way, then we submit that it would not be counterintuitive to think of her as being a genuine practical authority in relation to the student (the type of authority the student really ought to follow, regardless of whether moral blame is an appropriate attitude in a case of noncompliance).

Of course, given Raz's extremely attractive contention that part of what makes a life go well is the exercise of autonomy, ${ }^{39}$ the teacher who is in a position to actually know what is best for a student in some particular context would very often thus know that the student should make his own mistakes or creative decisions-this knowledge could itself be the basis of a legitimate, authoritative directive to be self-guided ('Be yourself!'). ${ }^{40}$ And if the teacher knows that what is best for her student is that he make his own decision, she would also rightly conclude that it would be a mistake for the student to fail to conform to the directive to be self-guided. The student would be demonstrating bad faith were he to pretend that the teacher was actually prompting him to choose X over Y, rather than make a decision for himself.

What is at issue in the cases we are wishing to focus on is not an obvious threat to another person's life or well-being - since, in such cases, people might, very plausibly, be thought to possess knowledge about what is in another person's self-interest-but, instead, ways to improve a healthy person's wellbeing. In cases where it is really clear that some act will radically undermine a person's well-being, we do not share Darwall's intuition that a directive cannot be authoritative. For example, when I yell at you to look out for the ice giving way on the river under your feet, my demand that you do so is, we think, quite authoritative (assuming we are not talking about a case of rational suicide), and this demand can be authoritative even if you are a complete stranger to me. Darwall might well reply that you are under no obligation to me to look out for the ice giving way; even so, you ought to pay attention to what I am saying, and you ought to look out for the ice giving way, and that, we contend, is enough to make my demand practically authoritative.

39 Raz, The Morality of Freedom (n 12) 390-5; Raz (n 11) 1015-16.

40 It is not clear what sense Darwall can make of such a directive, and how it appears authoritative to us: the teacher is clearly not undermining or interfering with the student's autonomy in this case. To flesh out the case a little, we might add that following the teacher's directive- that the student be selfguided-will lead the student away from a tendency to make bad faith decisions, hence making him better conform with reason in the long term. 
We are suggesting here that one's intuitions will most clearly shift if one attends to the case just described, and if one thinks about it in relation to practical authority in general. Focusing on a teacher who possesses this kind of knowledge should lead anyone who begins by sharing the intuitions that help Darwall build his case against Raz away from those intuitions. Once the reader's intuitions have shifted, we would also suggest that he or she consider the possibility that not only agents in the right kind of epistemic position can possess practical authority in cases involving the prudential reasons of other agents, but that even alarm clocks (as in the earlier example that Darwall discusses) might possess such authority, in virtue of them reliably issuing directives that make agents better conform with reasons that already apply to them. If we are right about this, even the directives of alarm clocks can constitute preemptive reasons. We do not have space to argue for this radical version of Raz's NJT here, ${ }^{41}$ but we believe it fits very well with the minimalist conception of authority outlined below.

There is a further dialectical move open to a defender of Darwall at this point. Our example of the lifestyle coach, or, indeed, Raz's example of the cooking teacher, might be thought to be problematic examples to use when arguing against Darwall, precisely because they are cases where a contractual relationship is entered into. It could be conceded by someone sympathetic to Darwall's approach that such coaches or teachers do possess practical authority, but that they only do so in virtue of the contractual relationship or promise entered into at the beginning of the relationship. And contracts or promises are clearly phenomena that are well suited to admit of a second-personal analysis, if anything is.

Suppose we distinguish between two cases: (1) unbeknownst to you, a stranger has somehow been collecting highly accurate information about you, and he now comes to you to provide you with a potentially life-changing directive; (2) you have voluntarily employed a lifestyle coach to collect highly accurate information about you, and, having collected this information, he now comes to you to provide you with a potentially life-changing directive. It is tempting to suppose that even if Darwall were to concede that the putative authority in (2) is a genuine authority, while denying that the putative authority in (1) is a genuine authority, he would still be in a dialectically stronger position than Raz, because he could explain the difference between (1) and (2) in second-personal terms (there is a contract or promise at play only in (2)), and because many people might intuitively judge that the stranger in (1) has no practical authority over you, no matter how accurate and detailed his information is about you. However, such a conclusion would actually be much too quick, because Raz has available to him a perfectly good alternative explanation as to why the person in (1) would not count as a practical authority.

For Raz, it is crucial that certain epistemic conditions be met, both by any putative authority and by the person who is being directed to follow that putative authority (although these conditions are not the same on each side of this relation). What is lacking in (1), and is present in (2), is epistemically well-grounded trust in 
the putative authority. ${ }^{42}$ We take it that expert lifestyle coaches (or cooking teachers, if you prefer) that we have employed will indeed be capable of being excellent epistemic authorities in the relevant domains, otherwise we would not (or should not) employ them. In any case, Raz can claim that their directives are only authoritative if both they and we meet appropriate epistemic conditions, and these conditions will normally not be met in cases like (1); hence we have an alternative explanation for the judgement that the stranger in (1) is not a practical authority. Given our earlier suggestions in this section as to how the intuitions that favour Darwall might be undermined, we think the dialectic now supports Raz, rather than Darwall.

Throughout this section we have been focusing on the intuitions that Darwall thinks he can rely on to undermine Raz's account of authority. However, we should not forget that Darwall does not merely rely on intuitions in the counterexamples he provides; he also provides an explanation of where Raz is going wrong, ie the wrong kind of reasons explanation. However, we thought it best to focus on basic intuitions above, precisely because this wrong kind of reasons explanation is a type of explanation that itself relies on non-dialectically-neutral intuitions to function well. We think Darwall's strongest dialectical move in his recent papers was to attempt to elicit particular intuitions by providing purported counterexamples, and that, given this goal, he chose his examples well. We just also happen to think this dialectical move is not, in the end, a successful one.

\section{THE MINIMALIST CONCEPTION OF PRACTICAL AUTHORITY}

What is the fundamental role of the concept of authority under contention meant to be? ${ }^{43}$ Raz tells us that the problem that he is focusing on when writing about author-

42 Raz thinks that there are epistemic conditions that must be met by any people that might be thought to be subject to an authority in order for the putative authority to count as legitimate with respect to those people (see eg 'The Problem of Authority' (n 11) 1025-6). Spelling out these epistemic conditions in a precise way is a very tricky business for the Razian: if he makes them too weak, it will seem implausible that there can be any practical authority in play (we fear that the mere condition of knowability, which Raz provides in 'The Problem of Authority', has this weakness), but if he makes them too strong, then it will turn out that what is really at play is mere epistemic authority, rather than practical authority (see the very interesting conclusion to 'On Respect, Authority, and Neutrality' (n 12) 300-1). We do not believe that the minimalist conception of authority necessarily suffers from this problem, since there may be nothing mere about epistemic authority on this conception (especially if it is further developed in the manner alluded to in $\mathrm{n} 2$ above).

43 We are using 'concept', 'conception', and 'role of the concept' as follows: first, we follow Rawls and others in using 'concept' to refer to any particularly central idea that all genuine participants in a philosophical dispute agree is the idea that they are providing alternative accounts of, and in using 'conception' to refer to any one of a number of differing accounts of the same idea (so Rawls takes it that his opponents will share his concept of justice, but will disagree with him as to whether justice as fairness is an accurate conception of justice; see John Rawls, A Theory of Justice (Harvard University Press, rev edn 1999 [1971]) 5); second, to give an account of the role of a concept is not, in itself, to provide the correct conception of that concept, but to endeavour to make sure that disputants have fixed on a particular concept, rather than some other concept, by providing some account of the role that the concept plays in our thinking-if the reference of a concept is not first fixed in this way, then, 
ity is simply 'the problem of the possible justification of subjecting one's will to that of another, and of the normative standing of demands to do so'. ${ }^{44}$ At first glance, this statement of the basic issue seems to be a very good place to start, and we think that Darwall would agree with it. Raz thinks that to claim that someone or something is an authority in relation to oneself is, first and foremost, to claim that they stand in a certain normative or justificatory relation to one's will (or merely purport to, in the case of merely de facto authority).

Raz claims that this feature of practical authority sets it apart from epistemic authority. Whereas the will plays an essential role in relation to action, it plays no such role in relation to belief, for we do not ordinarily choose what to believe. ${ }^{45}$ We do not deny that there is a difference here, but we are suspicious of the idea that the right place to begin analysing the concept of authority is with a statement of the problem of authority that entails, from the get-go, that there is a radical break between practical and epistemic authority. We would like to suggest instead that although the above way of pinning down what exactly the problem of authority is meant to be initially seems promising, the problem might instead be better stated in a more general way that involves simplifying Raz's statement as follows: the problem of authority is the problem of the possible justification of one being subject to directives originating outside of oneself. In the case of forming beliefs based on testimony, for example, the problem takes the particular form of determining when it is rational to believe the assertions of another, and the will of the other is relevant insofar as it might be directed by a desire to straightforwardly inform one of some truth, or, alternatively, by a desire to mislead. We contend that whether or not one's own will plays a role in one's being subject to the will of another is a secondary matter, so far as authority is concerned.

Once one distinguishes between being legitimately subject to directives that originate outside of oneself, and being legitimately subject to the will of another in a way that involves one's own will, it becomes very attractive to think of the type of authority that involves a relation between the wills of individuals as being simply a particular species of normative authority in general. It seems sensible to view practical authority as normative authority with respect to action in particular, since 'in a way that involves one's own will' appears to be a mere qualification of a more general, attractive statement of the province of normative authority. What about the move from 'subjecting ... to that of another['s will]' to 'being subject to directives originating outside of oneself'? Again, we take this to be a move that simply hinges on noticing that there is a more general problem in this territory than one that centres on the will of the other. ${ }^{46}$

for all we know, we might be talking past each other altogether, ie engaging in a merely verbal dispute (since it might then be the case that we are actually using two or more different concepts, rather than comparing different conceptions of a single concept).

44 Raz (n 11) 1003, emphasis added.

45 Ibid, 1034.

46 Once one makes this move, it becomes less problematic to confer authority on the alarm clock in the case discussed above. 
Raz would not accept this move of focusing on normative authority in general in order to understand practical authority, because he thinks one type of normative authority, epistemic authority (which he often calls 'theoretical authority'), is very different from practical authority in the following way: unlike practical authority, epistemic authority goes merely with being authoritative on some subject matter, rather than with having authority over another. ${ }^{47}$ If he were right about this, he would be right to resist our move of viewing practical authority as simply a species of normative authority in general; indeed one might then suspect that statements concerning 'epistemic authority' and statements concerning 'practical authority' involve the deployment of different concepts of authority altogether (this would be surprising, since it would suggest that the word 'authority' is ambiguous, when it does not seem to be). To make his case that epistemic authority does not involve having authority over another, he uses an example, but what he says about this example strikes us as misleading at best.

Raz writes, 'For example, some people are authorities on eighteenth-century farming methods, but they do not have authority over anyone. I know nothing about eighteenth-century farming methods and should take what they say as authoritative, but they do not have authority over me. ${ }^{\prime 4}$ We think it is true that on the assumption that one knows nothing about eighteenth-century farming methods and one has no reason to form any beliefs about eighteenth-century farming methods (apart from superficial beliefs such as that one is not interested in eighteenth-century farming methods), what an expert on such matters has to say about them will have no bearing, and plausibly should not have any bearing, on any of the beliefs one will form. But suppose one suddenly becomes interested in eighteenth-century farming methods; assuming that one is then in the business of forming beliefs about eighteenth-century farming methods (the reader can fill in the story to the requisite level of seriousness), surely the experts on the topic do indeed now have authority over oneself, with respect to the beliefs one forms about eighteenth-century farming methods.

Context matters when considering who has authority over oneself. Practical authority is no different from epistemic or theoretical authority in this respect. No military sergeant presently has authority over your actions (let us assume); but, presumably, there is a possible context in which a military sergeant would have such authority over you. Since practical authority is no different than epistemic authority in this respect, we believe Raz fails to establish that only practical authority is authority over someone.

In the same passage, Raz also claims that: (1) the distinction between merely de facto authority and legitimate authority does not exist in the case of theoretical authorities; and (2) only in the case of practical authority do we say that someone 'has authority' (rather than just 'is an authority'). We would suggest that (2) is an

47 Raz (n 11) 1034. Darwall likewise contends that epistemic authority is fundamentally different from practical authority, but he locates the difference in the first being fundamentally third-personal, while the second is essentially second-personal; see The Second-Person Standpoint (n 3) 12.

48 Raz (n 11) 1034. 
interesting, but ultimately superficial fact about our language (admittedly, it does sound a little odd to say 'that teacher has the authority to make little Jack believe that $\left.1+3=4^{\prime}\right)$. So far as (1) is concerned, we are a little surprised to find Raz making what seems, on the face of it, to be a straightforwardly false claim. Some Creationists are de facto epistemic authorities on the topic of fossils, for they strongly influence the beliefs of large numbers of followers who take them to be authoritative on the topic of fossils, but they nonetheless fail to be de jure epistemic authorities. To be fair to Raz, he might wish to claim that the correct thing to say about this example is that the Creationists are not epistemic authorities of any kind, not even de facto; however, this also seems false-if you were writing a book on Creationist teachers you might quite naturally write, 'their statements regarding fossils were authoritative with respect to the beliefs of their followers'; and you would be expressing a different kind of thought if you wrote, 'their statements regarding fossils were wrongly taken to be authoritative by their followers'.

If the reader still suspects that there is a crucial difference here, then perhaps that is because he or she is misled by the fact that in many contexts theoretical authorities may disagree on some topic, or the fact that in many contexts (such as in university classrooms) it is important for adults to think and reason about even the most seemingly settled of questions. That these facts can only mislead at this point should be obvious if one recalls the point that Raz makes that beliefs are not formed in a direct, voluntary matter. It may be that the will can play an important role in placing oneself inside or outside of a context where a particular expert has epistemic authority over one's beliefs (this may sometimes be rational to do, and sometimes irrational), but the will cannot (rationally) play a direct role in resisting epistemic authority, once one is in the relevant type of context.

It is true that a good theory of authority will need to adequately respect the autonomy of individual agents (this is a concern that plays a very prominent role in Darwall's criticisms of Raz, as we saw), but this is equally true in both the practical and epistemic domains: when it comes to the preemptive reasons that play a central role in Raz's service conception of authority, for instance, Raz would not want us to think that such reasons provide us with absolute duties to defer to others, or could ever be so strong or all-pervasive that they would undermine our rational capacities (since the whole point of such reasons is to allow us to better conform with reason in the long term). On the contrary, individuals will need to be able to rely on their own capacity for rational judgement to ensure that their suspension of any attempt to respond to certain types of reasons directly (rather than through the derivative reasons that authorities provide) is not inappropriate. Similarly, the ability to respond to epistemic authorities appropriately requires both a capacity to trust others, and a capacity to be able to judge when it is appropriate to suspend trust and call evidence into question.

How are we to understand the relation of authority de jure to normativity in general? We take it that the most basic category of normative facts are facts about what one ought to do, ought to believe, or ought to care about, etc (or ought not do, ought not believe, or ought not care about, etc). One ought to help people in need, and ought not believe that the world is flat. Within this category of ought-facts, some such 
facts are more basic than others: if utilitarianism were true, for instance, then the most general practical normative fact would be that one always ought to maximise total wellbeing; the fact that one ought to now help a particular person in need would be a derivative normative fact, whose truth would be explained by contingent, wholly non-normative, facts (to do with pleasures, pains, and the causes thereof), in conjunction with the utilitarian principle that states the fundamental practical normative fact. It is the job of normative ethical theory to articulate and defend principles that state the most basic or fundamental normative facts.

There are also facts about what normative reasons there are to do one thing or another. The concept of a reason stands to the concept of ought in the following two ways: (1) judgements about reasons are typically inputs to practical reasoning, whereas judgements about oughts are typically outputs; and (2) reasons are typically weighed up against each other, whereas oughts are (at least typically) verdictive, or all-things-considered. We take these to be basic truisms about the relation of normative reasons to oughts that are independent of any particular account of reasons. If I have promised to meet you to return your oboe to you at $2 \mathrm{pm}$ today, and I encounter a person in dire straits at $1.50 \mathrm{pm}$, on my way to meet you, I might weigh the reason I have to meet you against the reason I have to stop and help the person in need. I might rationally judge that one of these reasons is stronger than the other, then conclude that I ought to help the person in dire need.

Notice that it is an elementary fact about the phenomenology involved in such cases that I do not typically view the force of these reasons as resting inside of myself (whether in my will or my desires), but rather in external facts having to do with other people being in need, promises being made to others etc. ${ }^{49}$ Crucially, normative reasons, like oughts, have a quality of external authoritativeness about them. ${ }^{50}$ This is where one should start when thinking about authority, ie with the authority of normative facts.

The fact that a person in front of me is in dire straits (in the imagined scenario) is a reason to help her whose normative authority rests, at least in part, in this very external fact. If I asked 'but why help her?' you would be right to say, 'can't you see, she is in pain!'. The fact of her pain is (or gives rise to) a directive that I must, if I am reasonable, appropriately respond to. ${ }^{51}$ Recall that at the beginning of this sec-

49 By pointing this out, we are not trying to rule out the type of Humeanism that claims that all normative reasons rest ultimately on the psychology of the agent for whom they are reasons. Whether or not such Humeanism is tenable is beyond the scope of this paper. For the best recent defence of this type of Humeanism, see Mark Schroeder, Slaves of the Passions (Oxford University Press, 2007).

50 Defenders of Humean theories, at least if they possess the kind of sophistication that is required to make such theories plausible, need not deny this, nor need they view this quality as completely superficial, for they can agree with non-Humeans that the authority of reasons lies outside of one's conscious self, since, according to them, this authority will (in many cases, at least) be based in mental states that are distant, opaque and inflexible, compared to one's present, occurrent desires or one's present, active will.

51 Since reasons are (at least typically) pro tanto, they can be outweighed, so it is possible that the appropriate response will not be to act as the reason directs me to act; this will be because of countervailing considerations, and it would typically be inappropriate for me to fail to recognise, either in my deliberations or after the fact, that an overridden directive of which I am aware does still have some claim on me. 
tion of the paper we offered up a minimalist conception of practical authority, according to which the problem of authority is the problem of the possible justification of one being subject to directives originating outside of oneself. Now we can see that this is simply the problem of how it is that some facts provide agents with normative reasons for action, where attending to those reasons can lead agents to make correct judgements about what they ought to do, and where these reasons do not (or do not prima facie) rest on properties internal to the agent. Normative reasons are facts that constitute directives for rational agents. Some such facts will be facts about commands issued by entities (eg people or institutions), and in such cases their verbal directives may provide normative reasons of a derivative kind, but we should not begin by restricting the notion of a directive to that of a verbal directive.

\section{CONCLUSION}

We have argued that, in different ways, both Darwall's and Raz's conceptions of authority are based on too narrow an understanding of the problem of authority. This problem may be best construed as a problem that arises not first and foremost as a problem for one's will in relation to other people's wills, but as a problem of determining when one should align one's beliefs or actions with normative directives that have their source outside of oneself. We have not attempted to provide a general solution to this problem, and we have not attempted the more particular goal of explaining the nature or grounding of preemptive reasons, but we believe that whatever authority such reasons have is likely to be more general than Raz supposes, for we can look for features of this authority in the realm of belief, as well as the realm of action.

Darwall's second-personal account of authority is even narrower than Raz's. We find much more attractive and plausible an approach to the problem of authority that would start with a very general understanding of the authority genus, and then locate particular species of it. We have nothing against thinking of second-personal moral authority as one type of practical authority, but we do not believe that Darwall has provided us with adequate reasons to limit our understanding of practical authority in general to the second-personal standpoint, just as we do not believe that Raz has provided us with adequate reasons to limit normative authority to practical authority, or, indeed, the particular type of practical authority that he attempts to provide an analysis of with the two conditions that make up the service conception. 